\title{
Muralf
}

INTERNACIONAL

\section{A Política Externa Brasileira como Política Pública: a proposta de um Conselho Nacional e a experiência do Comitê Brasileiro de Direitos Humanos e Política Externa}

\section{Brazilian foreign policy as public policy: the proposal of a National Council and the experience of the Human Rights and Foreign Affairs Brazilian Committee}

\section{DANIELE COSTA DA SILVA ${ }^{1}$ MAGNO KLEIN ${ }^{2}$}

Resumo: Refletimos sobre a atual política externa brasileira a partir da constatação da sua diversificação em termos de agendas e atores. A pluralização de atores ocorre tanto no âmbito burocrático (fragilizando a tradicional primazia do Itamaraty) como na diversidade de atores não estatais (mídia, ONGs, empresários, etc.). Com a internacionalização da vida cotidiana, surgem novas demandas a respeito da agenda internacional, pressionando por novas dinâmicas nas práticas da política externa. Defendese que a política externa é uma política pública que, guardando sua especificidade, deve ser analisada como as demais políticas públicas brasileiras. A proposta de um Conselho Nacional de Política Externa e a recente experiência do Comitê Brasileiro de Direitos Humanos e Política Externa são demonstrações da importância de se levar em consideração as dinâmicas domésticas para uma compreensão adequada da política externa brasileira contemporânea.
Recebido em:

29 de Novembro de 2016

Received on:

November 29, 2016

Aceito em:

29 de Setembro de 2017

Accepted on:

September 29, 2017

DOI: 10.12957/rmi.2016.26899

Palavras-chave: política externa brasileira; análise de política externa; política pública.

Abstract: This paper delves into the current Brazilian foreign policy based on the assumption of its diversification in terms both of its agenda and actors. The pluralization of actors occurs not only in the bureaucratic scope (weakening the traditional Itamaraty's primacy), but also with other players from civil society (such as the media, NGOs, the business sector, and others). With the internationalization of daily life, new demands regarding the international agenda emerge, pressing for new dynamics on the practices of foreign policy. We defend that foreign policy is a public policy that, considering its specificity, should be analyzed such as others Brazilians public policies. The proposal of a National Council on Foreign Affairs and the recent experience of the Human Rights and Foreign Affairs Brazilian Committee are examples of the importance of reflecting upon domestic dynamics as a path to a better understanding of Brazilian contemporary foreign policy.

Keywords: Brazilian foreign policy; foreign policy analysis; public policy.

\footnotetext{
${ }^{1}$ Doutora em Ciência Política pelo Instituto de Estudos Sociais e Políticos (IESP/UERJ). Professora auxiliar da Universidade Estácio de Sá (UNESA). Endereço para correspondência: UERJ/PPGRI, Rua São Francisco Xavier, 524, Pavilhão - João Lyra Filho, $9^{\circ}$ andar, Bloco F, sala 9037, Maracanã, Rio de Janeiro, RJ - CEP: 20550-013. E-mail: daniellecsilva87@gmail.com

${ }^{2}$ Doutor em Ciência Política pelo Instituto de Estudos Sociais e Políticos (IESP/UERJ). Professor Adjunto de Política Externa na Unilab/BA (Universidade da Integração Internacional da Lusofonia Afrobrasileira). E-mail: magnoklein@gmail.com
} 


\section{Introdução}

Política pública é o conjunto de ações direcionadas a problemas sociais, econômicos e políticos por parte dos governos, sendo caracterizada pela disputa entre diferentes valores, interesses, normas e tipos de conhecimento dos vários atores sociais que buscam incidir nas agendas do Estado (Faria 2003, p. 23). No modelo de fluxos múltiplos proposto por John Kingdon $(1995)^{3}$, elas são entendidas em quatro etapas:

(1) a definição de uma agenda;

(2) a consideração das alternativas de ação;

(3) a escolha entre as possibilidades;

(4) a implementação da decisão.

As mesmas etapas estão presentes na política externa, então por que não aproximar os dois conceitos? Comprovação relevante de que política externa é política pública está no fato de que atores institucionais, sociais e econômicos a tratam nessa perspectiva, envolvendo-se em processos de disputa e barganha por influência nas práticas da agenda internacional do Estado da

\footnotetext{
${ }^{3}$ Seu estudo se concentra nos dois primeiros processos prédecisórios: a formação da agenda (agenda-setting) e as alternativas para a formulação das políticas (policy formulation) (Kingdon 1995, p. 3; Capella 2006, p. 25).
}

mesma maneira como atuam em sua agenda doméstica (Milani e Pinheiro 2013, p. 28). Essa constatação afeta as pesquisas acadêmicas: análises da política externa devem considerar o processo de elaboração em que demandas e conflitos de variados grupos domésticos incidem, como nas demais políticas públicas (Salomón e Pinheiro 2013, p. 41).

Ingram e Fiederlein (1988, p. 742) trazem para a análise das relações internacionais duas noções comuns aos estudos da política pública: primeiro, o processo de formulação das políticas (policy making) varia de acordo com a natureza do problema detectado, assim como reage de maneira diferente dependendo dos resultados das medidas iniciais; segundo, a influência dos atores no processo de formulação é diferente em cada estágio do ciclo político. Assim sendo, vários atores estatais e não estatais incidem na política externa de acordo com o tema (saúde, economia, defesa, etc.), com os estágios da política (formulação, avaliação, implementação) e com as características do quadro institucional.

A política externa também é sensível ao processo de politização, entendida como a intensificação do debate de ideias, valores e interesses e das disputas dentro das burocracias e entre os atores 


\section{Muralf}

INTERNACIONAL

por maior influência. Esses conflitos a inserem na conflituosa arena do debate político doméstico (Milani e Pinheiro 2013, pp. 29-30; Lowi 1966, p. 323). A presença de vários atores com distintos poderes de agência (em termos de acesso a informações, nível de participação na formulação da política e capacidade legal ou constitucional de agir) colabora para tornar a política externa mais plural e democrática, agregando valores, interesses e demandas presentes na sociedade.

O discurso da política externa como política de Estado, tão comum nos debates ao redor da relações internacionais brasileiras, mascara as sempre presentes disputas políticas em seu processo decisório e, em particular, as diferentes capacidades dos atores políticos de incidir em sua formulação. Por isso, a defesa da natureza de política pública da política externa resgata o questionamento a respeito de um pretenso interesse nacional e como se definem as prioridades da ação internacional dos Estados.

De acordo com os entendimentos tradicionais do pensamento realista, o interesse nacional seria objetivamente definido, identificado em bases materiais e separado do processo político doméstico. Esta percepção é alvo de várias críticas relevantes por
Mural Internacional

V. 7 | N. 2

JUL-DEZ 2016 construtivistas, behavioristas e outros grupos. Os liberais negam a premissa de que é possível separar interesses nacionais e particulares. Embora não haja entre esses teóricos uma definição explícita a respeito do conceito, Battistella (2002) conclui que, segundo os entendimentos gerais do liberalismo, o interesse nacional é aquilo que a nação define que ele é. Ou melhor, para autores liberais como Andrew Moravcsik (2008), os interesses expressos nas políticas externas são definidos por aqueles atores sociais com maior capacidade de influenciar as ações estatais. Neste entendimento, não haveria separação entre interesses nacional e privado. Os interesses nacionais refletiriam as demandas sociais, e por isso não seriam unitários, mas múltiplos.

Milner (1997) e Putnam (1988) reforçam o argumento a respeito da ascendência do âmbito doméstico sobre $o$ internacional na formulação da política externa, em particular em contextos democráticos. Putnam (1988) aponta como, nas negociações internacionais, a proposta conduzida pelo ator estatal é gestada independentemente das preferências do negociador, sendo definida pelos atores domésticos com acesso privilegiado ao aparelho de governo. Milner (1997), por sua vez, propõe uma interpretação mais 
elaborada deste enquadramento ao levar em consideração as interações entre os diferentes poderes estatais e a participação dos atores da sociedade civil. Desse modo, as distintas capacidades dos atores e as particularidades institucionais são fatores explicativos relevantes da agenda de política externa dos Estados.

Ainda assim, as políticas externas guardam especificidades diante das demais políticas públicas, afinal são implementadas para além das fronteiras estatais. Ao construírem o elo entre o internacional e o doméstico, possuem a natureza de uma política sui generis: são ao mesmo tempo política de Estado (agendas de longo prazo e amplo consenso social) e também política pública (Milani 2015, p. 60).

\section{A política externa brasileira e suas inflexões recentes}

Durante as últimas décadas, a política externa brasileira vem passando por transformações que evidenciam o caráter político do seu processo de formulação e que só podem ser plenamente compreendidas a partir do entendimento de que ela é também uma política pública. Novas agendas e novos atores estão presentes nas práticas da política externa brasileira e as explicações para estas transformações são tanto de natureza sistêmica quanto originárias das especificidades domésticas.

Vivemos um período de transformações na maneira como a política externa é entendida e formulada (Hill, 2003). Em parte por influência das transformações recentes no sistema internacional (como o fim da Guerra Fria, a internacionalização da vida cotidiana e o fenômeno da globalização), os países vêm lidando com uma maior complexidade na formulação e execução de suas políticas externas. As fronteiras entre o interno e o externo se "dissolvem", havendo uma crescente mistura entre os ambientes doméstico e internacional nas políticas dos países.

Uma das mudanças mais significativas seria o "transnacionalismo", a maior participação de atores transnacionais na vida internacional (instituições religiosas, organizações da sociedade civil, grupos terroristas etc.). Surgem novas constituencies, desta vez externas, às quais os estadistas podem ter que se reportar (como a opinião pública internacional, partidos políticos afins etc.). Tais mudanças, somadas às novas práticas como a doutrina de intervenção humanitária (criando exceções nas noções de soberania e autoafirmação dos povos), fazem com que a capacidade dos Estados em agir autonomamente no sistema 


\section{Muralf}

INTERNACIONAL
Mural Internacional

V. 7 | N. 2

JUL-DEZ 2016 internacional seja cada vez mais minada. A política externa é atualmente uma área mais complexa e mais contestada, porém está longe de ser insignificante e de desaparecer. Todas as noções centrais da política moderna estão hoje implicadas com a política externa, que não pode ser entendida como um espaço isolado e livre de constrangimento.

O processo decisório em política externa no Brasil vem passando por um processo análogo de transformações decorrentes de mudanças internacionais e domésticas (com ênfase no retorno ao regime democrático em 1985). Pinheiro (2009) indica dois desses fenômenos. O primeiro seria a descentralização horizontal. A tradicional centralidade do Presidente da República e do Ministério das Relações Exteriores na formulação e condução da política externa não teria sido alterada, mas outras agências burocráticas vêm tendo maior protagonismo em assuntos internacionais. Quase todos os ministérios contam com assessoria internacional, por exemplo. Também houve a expansão da diplomacia subnacional, realizada por Estados e municípios. O segundo fenômeno é definido como verticalização controlada e faria referência a maior participação de atores da sociedade civil em vários pontos da agenda da política externa.

Esses processos são reforçados pelo lento aprofundamento da democracia e maior participação social nas políticas públicas. No caso da política externa, a Constituição de 1988 foi um marco tímido nesse processo, mantendo a primazia do chefe do poder Executivo na formulação das diretrizes das relações internacionais. A condução da política externa no Brasil, sua formulação e decisão, manteve-se centrada no Poder Executivo, com o Poder Legislativo desempenhando tarefas como aprovação das decisões do Executivo sobre assinatura de tratados, na manutenção das relações com outros Estados e na participação do país nas organizações internacionais. Todavia, a participação, ou interesse em participar, do Poder Legislativo na política externa brasileira tende a variar de acordo com a repercussão interna da agenda: quanto maior o impacto, maior o interesse dos parlamentares em participar do processo decisório (Castro Neves 2006, p. 379). Já o Poder Judiciário se caracteriza pela sua eventual participação ad hoc nas fases de implementação e avaliação de tratados (Sanchez et al 2006, p. 131).

Com a redemocratização, houve a criação e consolidação de espaços de interlocução entre Estado e sociedade 
civil, com a criação de conselhos gestores de políticas públicas, conquistas dos movimentos sociais no esforço por uma gestão pública mais democrática (Teixeira 2002, p. 107). Isso permitiu que diversos atores da sociedade civil tivessem a possibilidade de cobrar mais transparência e mecanismos formais de participação na formulação e implementação de políticas públicas, o que veio a ser utilizado também nas agendas da política externa, em áreas como comércio e direitos humanos. Questões compreendidas como low politics também ganharam relevância e espaço nas discussões da política externa, em especial entre 2003 e 2014, com o aprofundamento da participação de organizações não estatais (de forma informal e esporádica) na formulação das agendas de política externa (Milani 2012, p. 41; Holzhacker 2015, p. 13). Além disso, o fenômeno da internacionalização da vida cotidiana e o aprofundamento da inserção internacional brasileira aumentaram os efeitos distributivos da política externa e o interesse dos diversos atores sociais em terem seus interesses representados na ação internacional do país.

O insulamento burocrático do MRE é desafiado pela pluralização dos atores e cada vez mais tende a ser disfuncional, o que induz à modernização dos arranjos institucionais existentes para que levem em conta os novos atores e interesses domésticos na política externa e para que estejam mais abertos ao debate público (Lima 2005, pp. 7-8).

\section{O longo caminho até a} democratização: a proposta de um Conselho Nacional e a experiência do Comitê Brasileiro de Direitos Humanos e Politica Externa

No discurso, o Itamaraty se mostra disposto a colaborar com medidas de maior transparência, como na iniciativa de criação de um Livro Branco, documento que reuniria as diretrizes para a atuação internacional do país. Um primeiro passo para sua concretização foi, após forte pressão social, a convocação dos "Diálogos de Política Externa",, cujos resultados serviriam de base para a elaboração do documento, de acordo com o MRE.

Em termos de maior participação social na política externa, entidades da sociedade civil propuseram a implementação do CONPEB (Conselho Nacional de Política Externa), organismo que seria composto por representantes da sociedade civil e agências burocráticas com o objetivo de

\footnotetext{
4 Conjunto de debates realizados entre os dias 26 de fevereiro e 2 de abril de 2014, em Brasília.
} 


\section{Muralf}

INTERNACIONAL
Mural Internacional

V. 7 | N. 2

JUL-DEZ 2016 assessorar o Poder Executivo e garantir maior participação popular, controle social e democratização da política externa, tanto em suas etapas de formulação e execução quanto na tarefa de monitorar e avaliar os resultados. A realização da Conferência Nacional 2003-2013: Uma nova política externa (2013), pelo Grupo de Reflexão sobre Relações Internacionais ${ }^{5}$ em parceria com a Universidade Federal do ABC, foi uma etapa importante na defesa desse organismo. Na fala de abertura, representantes entregaram ao então ministro Antonio Patriota uma carta em que destacavam o fato de o país não ser dotado de um mecanismo institucional de consulta e participação social na formação da política externa (GR-RI, 2014).

Ao receber a carta, Patriota mostrou-se favorável à institucionalização do órgão. Postura semelhante teve seu sucessor, Luiz Alberto Figueiredo. Com uma nova troca da liderança no MRE, após o início de um novo mandato presidencial de Dilma Rousseff, no entanto, os primeiros passos do novo ministro Mauro Vieira não sinalizaram movimento em prol da

\footnotetext{
5 O Grupo de Reflexão sobre Relações Internacionais é constituído por pesquisadores e pessoas que atuam no campo das relações internacionais a partir de movimentos e organizações sociais, partidos políticos, ONGs, instituições acadêmicas, de pesquisa e de governo. Mais informações no site do Grupo: http://brasilnomundo.org.br/ .
}

institucionalização do CONPEB. Com a redução da prioridade da agenda internacional por parte do governo e enfrentando grave crise institucional, a demanda pelo CONPEB foi deixada para segundo plano pelo novo ministro e aparentemente não é uma prioridade da nova gestão Temer.

O MRE já realiza consultas informais com alguns grupos da sociedade em determinados casos. A novidade aqui estaria na existência de um mecanismo permanente, estruturado, com funções consultivas e comunicativas para ouvir a sociedade, trazendo novas ideias e esclarecendo informações (Patriota 2013, p. 15).

O projeto de uma instituição política consultiva permanente encontra resistência dentro do MRE, que argumentaria que a política externa teria um caráter particular das demais políticas públicas. Figueira (2010, pp. 20-21) salienta a presença no ministério de duas lógicas administrativas: a lógica da mudança, voltada para a maior porosidade, diminuição do insulamento burocrático e incorporação de preceitos gerenciais e demandas oriundas dos cidadãos, e a lógica da resistência, voltada para a manutenção do status $q u o$, da centralização administrativa hierarquizada e rígida. A resistência de setores do MRE ao projeto de uma 
instituição consultiva refletiria esse embate de lógicas administrativas; uma seguindo visão mais cosmopolita, a outra, mais soberanista e tecnocrática, em que o poder de decisão estaria centrado no Poder Executivo e os diplomatas pensariam e executariam taticamente as ações internacionais do Estado.

A postura reativa também é uma resistência a assumir o caráter de política pública da política externa. Ativistas defendem que mecanismos de consulta e controle social institucionalizados contribuiriam para que a política externa não siga dependendo predominantemente das pessoas que dirigem as instituições, com o controle social buscando compensar as desigualdades de poder em âmbitos como o político, o econômico e o midiático (Menezes 2012, p. 90).

A experiência do Comitê Brasileiro de Direitos Humanos e Política Externa (CBDHPE) é um exemplo relevante de atuação conjunta entre governo e sociedade civil na elaboração e fiscalização da agenda de direitos humanos da política externa brasileira. O CBDHPE, oficialmente criado em 31 de maio de 2006 na Câmara dos Deputados em Brasília, é um fórum de discussão e grupo de acompanhamento da política externa formado por entidades da sociedade civil e do Estado com o objetivo de ampliar a participação cidadã e o controle democrático da política externa brasileira no campo dos direitos humanos. O objetivo principal do CBDHPE seria o fortalecimento da participação cidadã e $\quad$ o controle democrático desse campo da política externa brasileira, dedicando-se ao acompanhamento da negociação, ratificação e implementação de instrumentos regionais e internacionais, ao acesso à informação sobre a política externa de direitos humanos, e buscando influenciar e monitorar os processos de tomada de decisão da política externa que possam gerar impactos na proteção e promoção dos direitos humanos em âmbito nacional ${ }^{6}$. Dentre algumas das ações relevantes realizadas pelo CBDHPE assinala-se a participação em audiências públicas sobre a agenda brasileira em direitos humanos, o constante monitoramento sobre a elaboração dos relatórios da Revisão Periódica Universal do Brasil no Conselho de Direitos Humanos (CDH) das Nações Unidas, o envio de cartas de compromisso com os direitos humanos aos candidatos à Presidência da República (nas eleições de 2010 e 2014)

\footnotetext{
${ }^{6}$ Informações retiradas do site do Comitê Brasileiro de Direitos Humanos e Política Externa, disponível em: http://dhpoliticaexterna.org.br/
} 


\section{Muralf}

INTERNACIONAL
Mural Internacional

V. 7 | N. 2

JUL-DEZ 2016 e a realização de videoconferências públicas periódicas entre os membros do CBDHPE e representantes do MRE, as quais permitem o debate $\mathrm{e}$ a transparência da agenda política do Brasil nas sessões do $\mathrm{CDH}$, como, por exemplo, a situação das resoluções lideradas ou apoiadas pelo Brasil.

Mesmo havendo este espaço institucionalizado para a participação de atores sociais, ainda paira a incerteza sobre a capacidade dos atores não estatais em incidir no processo decisório. Em pesquisas anteriores, buscamos conhecer melhor o funcionamento do CBDPHE por meio de entrevistas e análises de suas reuniões $^{7}$ (Silva, 2016), onde foi possível refutar os pressupostos de que o referido órgão não era amplamente aproveitado para a assimilação de propostas e apresentava um funcionamento meramente de avaliação em relação à condução da política externa brasileira em direitos humanos.

Embora tenha desempenhado inicialmente uma atuação esporádica de monitoramento das ações do Estado na condução da política externa em direitos humanos com pouca interlocução direta entre ONGs e o MRE, o Comitê passou

\footnotetext{
${ }^{7}$ A referida pesquisa analisou o posicionamento e a opinião de ONGs integrantes do CBDHPE a respeito da agenda de direitos humanos da política externa brasileira.
}

por um fortalecimento institucional após o afastamento da Comissão de Direitos Humanos e Minorias da Câmara dos Deputados (CDHM) em 2013 ${ }^{8}$, ocasionando uma valorização das atividades do CBDHPE e uma maior interlocução da sociedade civil com o MRE. Essa mudança somada a outras, como a implementação de reuniões por videoconferências e a disposição da então chefia da Divisão de Direitos Humanos do Itamaraty (DDH-MRE) em investir no organismo para dialogar com a sociedade civil, transformaram o CBDHPE em um espaço de interlocução viável para a participação das entidades da sociedade civil na elaboração da agenda de direitos humanos da política externa brasileira.

Constatamos em pesquisa anterior que a importância do organismo é reconhecida pelos atores sociais que atuam nele. Eles avaliam o CBDHPE como exercendo um papel importante em prol da democratização da política externa em direitos humanos e como um locus de inúmeras possibilidades de ação. $\mathrm{O}$ CBDHPE também foi assinalado como um dos poucos espaços institucionais

\footnotetext{
8 O afastamento do CDHM ocorreu devido ao posicionamento conservador e contrário aos direitos humanos da referida instituição durante a presidência do deputado federal Marco Feliciano (PSC/SP). O desligamento do CDHM foi fundamentado pelo seu afastamento dos princípios de promoção e proteção aos direitos humanos, se fechando à participação da sociedade.
} 
com legitimidade por parte do poder público em que é possível apresentar pautas específicas patrocinadas por cada organização, cobrindo a diversidade temática da agenda de direitos humanos.

Outra competência do CBDHPE referese à politização da construção do discurso brasileiro sobre os direitos humanos, ao possibilitar às entidades participantes apresentarem seus discursos e suas perspectivas sobre os direitos humanos e debaterem com o MRE. Dada essa competência, o CBDHPE foi considerado uma instituição pioneira em pensar os direitos humanos na política externa brasileira e em colocar a política externa em discussão como uma política pública ao alcance de todos, multilateralizando o debate e dando visibilidade aos propósitos e meios de ação da agenda de direitos humanos da política externa brasileira.

No entanto, as entidades participantes reconhecem algumas deficiências. A Conectas Direitos Humanos, por exemplo, aponta dificuldades de fazer o Poder Executivo colocar as propostas em prática. Outro fator negativo, assinalado pelo IDDH, é a falta de engajamento das próprias ONGs, e de outros atores civis não integrantes, em atuar na instituição. Vários motivos estariam relacionados a essa ausência.
Para a Secretaria Geral, a queda na participação civil seria também resultado da sobrecarga de atividades em que as ONGs estão envolvidas. Esta explicação é dada pelo INESC, por exemplo, para quem, além do excesso de atividades, pesou uma possível descrença sobre a efetividade do CBDHPE.

Em relação à interlocução entre sociedade civil e Estado, a Justiça Global ressalta que ainda não é claro o grau de inclusão das ideias e das propostas apresentadas pelas organizações civis participantes do CBDHPE nas posições ou ações efetivas na política. Mesmo com o aprofundamento da democratização da política externa, essa ainda é uma política pública pouco transparente, pesando fatores como o desconhecimento das prioridades do MRE na área dos direitos humanos, além da incerteza sobre se a capacidade das propostas apresentadas pelos membros do CBDHPE influenciarem os tomadores de decisão.

Em entrevista, Pedro Saldanha, então diplomata chefe da DDH-MRE ${ }^{9}$ e encarregado de acompanhar e participar das atividades do CBDHPE, reiterou que a prática do diálogo com as ONGs

9 O diplomata foi entrevistado no dia 12 de fevereiro de 2016, na DDH no Palácio do Itamaraty, em Brasília. 


\section{Muralf}

INTERNACIONAL

não significa a completa incorporação pelo MRE do que lhe é dito ou apresentado. A política externa teria a peculiaridade de lidar com fatores internacionais, além do fato de o posicionamento do Brasil ser construído gradualmente pelo diálogo e pela avaliação da posição dos demais atores e países. Um exemplo de interesses conflitantes de atores domésticos são as posições de empresas e de entidades de direitos humanos, disputa considerada pelo chefe da DDH-MRE como polêmica e de alta complexidade.

De acordo com o chefe da DDH, as contribuições e demandas da sociedade civil são encaminhadas aos tomadores de decisão seguindo o rito interno hierárquico do MRE, ou seja, a sua escala decisória intraburocrática ${ }^{10}$ : após as reuniões por videoconferência, ele, como representante do MRE nas reuniões do CBDHPE, discute com o diretor do Departamento de Direitos

\footnotetext{
10 A escala decisória intraburocrática do MRE obedece à estrutura organizacional que se inicia com a subdivisão do ministério em grandes eixos de atuação, definidos por critérios geográficos e temáticos, resultando em sete Subsecretarias que compõem o eixo estrutural e funcional do MRE abaixo das funções do Secretário Geral e do Ministro de Estado. Assim, a escala decisória intraburocrática, altamente hierarquizada, se inicia com os Chefes de Divisões, que respondem ao Chefe de Departamento, que estão submetidos ao Subsecretário Geral, o qual responde ao Secretário Geral que articula juntamente com o Ministro de Estado e seus Chefes de Gabinete as decisões de política Externa, tendo como ápice institucional a Presidência da República (Figueira 2010, p. 13). O organograma dos níveis burocráticos do MRE encontra-se disponível em: http://www.itamaraty.gov.br/images//organograma/2016020 3-Organograma-port.pdf .
}

Mural Internacional

V. 7 | N. 2

JUL-DEZ 2016
Humanos e Temas Sociais (setor da Subsecretaria-Geral Política I), que por sua vez, apresenta tais demandas para a Secretaria Geral das Relações Exteriores e ao Gabinete do Ministro das Relações Exteriores. Através desse caminho burocrático é que as demandas e contribuições das ONGs chegariam ao nível dos efetivos tomadores de decisão (dentro do MRE) da política externa brasileira, cabendo a eles a decisão sobre a incorporação ou não dos apontamentos das organizações participantes do CBDHPE, juntamente com os demais interesses oriundos de outros atores da sociedade civil, tais como os empresários, na preparação, por exemplo, das instruções a serem enviadas à delegação brasileira em Genebra definidoras da atuação do Brasil no CDH.

Ainda segundo o diplomata, apesar de limitações estruturais, como a possibilidade de reunir seus diversos participantes em um mesmo espaço físico, o CBDHPE seria uma saída inteligente para a canalização do diálogo com a sociedade civil, contribuindo com informações a serem consideradas na formação das posições do Brasil nas arenas internacionais e colaborando para que a política externa brasileira seja um reflexo de sua sociedade civil. 
A forma como o diálogo é desenvolvido, via contato direto com a Secretaria Geral do CBDHPE e, principalmente, por meio das videoconferências ${ }^{11}$ realizadas seguindo o calendário de sessões do Conselho de Direitos Humanos da ONU, foi apontada pelo diplomata como um mecanismo exemplar para apresentar a agenda do $\mathrm{CDH}$ e o posicionamento do Brasil em relação a ela, e para a captação dos aportes e demandas da sociedade civil. O diplomata-chefe da DDH lembrou a intenção do MRE de promover futuramente reuniões presenciais regulares com as ONGs integrantes do CBDHPE.

A iniciativa do CBDHPE de realizar videoconferências partiu da ideia de institucionalizar a interlocução com o governo antes e depois das sessões do CDH. Tais reuniões possuem duas etapas. Na primeira, quando o encontro acontece anteriormente à sessão do $\mathrm{CDH}$, ocorrem as apresentações das prioridades do MRE e da (antiga) SDH para o referido período. No caso de ser realizado após as sessões, assume uma dinâmica de prestação de contas das ações do Brasil, expondo a avaliação do governo sobre os desdobramentos das

\footnotetext{
${ }^{11}$ As reuniões são realizadas por meio dos equipamentos de videoconferência disponíveis nas sedes do Ministério Público Federal em várias cidades, entre elas: Brasília, Belém, Curitiba, Florianópolis, Manaus, Rio de Janeiro, Recife e São Paulo.
}

prioridades, os motivos das ações e dos posicionamentos assumidos multilateralmente. Na segunda etapa, as organizações da sociedade civil (integrantes do CBDHPE ou não) apresentam perguntas aos representantes estatais buscando informações ou justificativas para os posicionamentos do país, além de apresentarem observações, questionamentos, cobranças e recomendações.

O CBDHPE é um promotor do diálogo entre Estado e sociedade civil e espaço para a exposição de demandas pelas ONGs, do acolhimento de suas posições pelo Itamaraty e também de transparência. Por meio dele, o MRE presta contas das posições internacionais brasileiras, considera sugestões de pautas e recebe informações que aprimorem sua atuação. Confirma-se assim a observação de Santoro (2012) sobre a possibilidade da existência de um espaço de ação conjunta entre governo e sociedade civil na agenda internacional de direitos humanos.

Concluiu-se então que o CBDHPE funciona tanto como via institucional doméstica viabilizadora da participação civil na formulação da agenda de direitos humanos quanto como órgão fiscalizador por meio do qual as ONGs regulam as ações estatais, sem ameaçar 


\section{Muralf}

INTERNACIONAL

a liderança do governo e do MRE no processo de formulação da política externa. Ao contrário, trazem mais legitimidade para os posicionamentos internacionais do Brasil. Os integrantes do CBDHPE possuem certo poder de agência na política externa brasileira em direitos humanos, com reconhecimento por parte da divisão de direitos humanos do MRE, que demonstra disposição para ouvir e incluir na agenda suas demandas dentro das limitações e particularidades da política externa. A atuação de atores domésticos e não estatais, no entanto, ainda não dispõe de um órgão institucionalizado que os permitam incidir no processo de formulação da política externa brasileira como um todo.

É importante assinalar que a participação das entidades da sociedade civil numa instância participativa de elaboração das posições internacionais do país não as torna agentes tomadores de decisão, uma vez que sua participação está limitada às fases de pré-decisão e pós-decisão (fiscalização e crítica). Todavia, elas são sim atores políticos capazes de pressionar os tomadores de decisão, o governo e o MRE, apresentando propostas e alternativas, e também criticando políticas.

\section{Conclusão}

Mural Internacional

V. 7 | N. 2

JUL-DEZ 2016

Uma vez que os determinantes domésticos de um Estado são vitais para a formulação da política externa, em especial na atual conjuntura de pluralização e maior influência de atores domésticos na agenda internacional brasileira, e sua consequente politização, logo, a política externa pode ser entendida como uma política pública peculiar, com uma face de política de Estado preocupada com questões mais perenes, como a proteção do território, defesa da soberania, proteção dos cidadãos brasileiros no exterior, entre outras.

Aponta-se a democratização da política externa brasileira - ou seja, a diversificação dos atores envolvidos-, e a politização - entendida como a disputa entre ideias e interesses. A agenda de direitos humanos da política externa brasileira é um notável exemplo do processo de politização ocasionado por sua democratização.

Mesmo com a boa experiência do CBDHPE em democratizar a agenda da política externa, algumas questões permanecem em aberto: como institucionalizar de forma efetiva $o$ diálogo entre de um lado os atores não estatais e de outro a alta cúpula do MRE e os assessores da Presidência da República de forma a garantir maior transparência no processo de elaboração 
dessa política e na maior assimilação das demandas oriundas dos cidadãos? Qual será o caminho a ser trilhado até avançarmos a democratização da política externa, tratando-a como a política pública que ela é?

\section{Referências Bibliográficas}

Battistella, D. (2002). "L'intérêt national: Une notion, trois discours", in. Charillon, Frédéric (dir.). Politique Etrangère: Nouveaux regards. Paris: Sciences Po, pp. 139166.

Capella, A. C. N. (2006). "Perspectivas Teóricas sobre o Processo de Formulação de Políticas Públicas”, in. Revista Brasileira de Informação Bibliográfica em Ciências Sociais - BIB. São Paulo: no 61, pp. 25-52.

Castro Neves, J. A. de. (2006). "O Congresso Nacional e a Política Externa", in. Oliveira, H. A. de; Lessa, A. C. (Org.). Relações internacionais do Brasil: temas e agendas. Vol. 2. São Paulo: Saraiva.

Faria, C. A. P. (2003). "Ideias, conhecimento e políticas públicas: Um inventário sucinto das principais vertentes analíticas recentes", in. Revista Brasileira de Ciências Sociais. Vol. 18, $\mathrm{n}^{\circ} 51$.

Figueira, A. R. (2010). "Rupturas e continuidades no padrão organizacional e decisório do Ministério das Relações Exteriores", in. Revista Brasileira de Política Internacional. Vol. 53, $\mathrm{n}^{\circ}$ 2, pp. 5-22.

GR-RI. (2014). "Carta entregue ao ex-chanceler Antonio Patriota, durante a Conferência, pelo Grupo de Reflexões em Relações Internacionais", in. Maringoni, G.; Schutte, G. R.; B, G. (Orgs). 2003-2013 Uma Nova Política Externa. Tubarão: Ed. Copiart.

Hill, C. (2003). The Changing Politics of Foreign Policy. Palgrave Macmillan.

Holzhacker, D. O. (2015). “A participação de atores não estatais na Política Externa Brasileira entre 2003 e 2014", in: Anais do $5^{\circ}$ Encontro Nacional da ABRI. Belo Horizonte, 29 a 31 de julho, 2015. Disponível em: http://www.encontronacional2015.abri.org.br/site/anaiscomplementares?AREA=14\% 20\#D . Acessado em: 10 de agosto de 2015. 


\section{Muralf}

INTERNACIONAL

Mural Internacional

V. $7 \mid$ N. 2

JUL-DEZ 2016

Ingram, H. M.; Fiederlein, S. L. (1988). "Traversing Boundaries: a Public Policy Approach to the Analysis of Foreign Policy”. Political Research Quarterly, vol. 41, $\mathrm{n}^{\circ}$ 4, pp. 725-745.

Kingdon, J. (1995). Agendas, alternatives, and public policies. Nova York: HarperCollins College Publishers, $2^{\mathrm{a}}$ Edição.

Lima, M. R. S. de. (2005). "A política externa brasileira e os desafios da cooperação Sul-Sul”, in. Revista Brasileira de Política Internacional. nº 48 (I): pp. 24-59.

Lowi, T. (1966). "Making Democracy Safe for the World: National Politics and Foreign Policy”, in. ROSENAU, James (Ed.). Domestic Sources of Foreign Policy. Nova York: Free Press, pp. 295-332.

Menezes, T. M. de. (2012). "O Brasil e o Conselho de Direitos Humanos das Nações Unidas: a participação social em ampliação”, in. Milani, C. R. S.; Pinheiro, L. (orgs). Política externa brasileira: As práticas da política e a política das práticas. Rio de Janeiro: Editora FGV, pp.71-92.

Milani, C. R. S. (2012). "Atores e agendas no campo da política externa brasileira de direitos humanos", in. Milani, Carlos R. S.; Pinheiro, L. (Orgs). Política externa brasileira: As práticas da política e a política das práticas. Rio de Janeiro: Editora FGV, pp. 33-70.

Milani, R. S. C. (2015). “Política Externa é Política Pública?”, in. Insight Inteligência. Ano XVIII, nº 69, abril/maio/junho de 2015, pp. 57-75.

; Pinheiro, L. (2013). "Política Externa Brasileira: Os Desafios de sua Caracterização como Política Pública", in. Contexto Internacional. Rio de Janeiro, vol. $35, \mathrm{n}^{\mathrm{o}}$ 1, janeiro/junho, pp. 11-41.

Milner, H. V. (1997). Interests, Institutions and Information, Domestic Politics and International Relations. Princeton University Press, pp. 33-66.

Moravcsik, A. (2008). "The New Liberalism", in. Reus-Smit, Christian; Snidal, Duncan (ed.). The Oxford handbook of international relations. Oxford: Oxford, pp. 234-254. 


\section{8}

Patriota, A. de A. (2013). "Diplomacia e democratização", in. Política Externa. Vol. 22, n 2, Outubro/Novembro/Dezembro, pp. 9-16.

Pinheiro, L. (2009). Autores y actores de la política exterior brasileña. Foreign Affairs Latinoamérica, vol. 9, no 2, p. 14-24.

Putnam, R. (1998). Diplomacy and Domestic Politics: The Logic of Two-Level Games. International Organization, Wisconsin: v.42, n.3, p.427-59.

Salomón, M.; Pinheiro, L. (2013). “Análise de Política Externa e Política Externa Brasileira: trajetória, desafios e possibilidades de um campo de estudos", in. Revista Brasileira de Política Internacional. Vol. 56 (1): pp. 40-59.

Sanchez, M. R. et al. (2006). "Política Externa como política pública: uma análise pela regulamentação constitucional brasileira (1967-1988)", in. Revista de Sociologia e Política. Curitiba: n²7, pp. 125-143.

Santoro, M. (2012). "Democracia e Política Externa no Brasil”, in. Revista Estudos Políticos. No4, vol.1, pp. 95-105.

Silva, Danielle Costa da. A atuação das organizações não governamentais na agenda de direitos humanos da política externa brasileira. 2016. 358f. Tese (Doutorado em Ciência Política). Instituto de Estudo Sociais e Políticos, Universidade do Estado do Rio de Janeiro, Rio de Janeiro, 2016.

Teixeira, A. C. C. (2002). "A Atuação das Organizações Não Governamentais: entre o Estado e o Conjunto da Sociedade", in. Dagnino, Evelina (Org.). Sociedade Civil e Espaços Públicos no Brasil. São Paulo: Paz e Terra, pp. 105-142. 